\title{
The study of the influence between informal learning places and interactive activities in campus group based on spatial configuration
}

\author{
Sheng $\mathrm{Li}^{\dagger}$, Fang Wu*, Jia-Li Wu, Ke Xie and Yu-Peng Xu \\ Department of Architecture, School of Engineering, \\ Zhejiang University City College \\ Hang Zhou, 310011, China \\ E-mail:whirlss@163.com \\ *Corresponding author. \\ E-mail:elcroquis@163.com \\ www.zucc.edu.cn
}

\begin{abstract}
Informal learning is an essential part of students' active learning in higher education. They are sustainable development's representations to create favorable informal learning space and energize students in colleges, which is of great significance to higher education At present, colleges' planning designs focus more on landscapes and architectural forms instead of superior informal learning places. This paper analyzes the correlation between spatial configuration and the network of interactions, on the basis of which provides layout and strategies, putting into use with empirical study.

Keywords: College Informal Learning Spaces; Spatial Configuration; Interactive Activity; Learning Engagement; Sustainability.
\end{abstract}

\section{Background and Introduction}

\subsection{Research background}

The contemporary higher education is facing great changes. For example, the wide application of information technology, learning changes in the characteristics of the subject, learning paradigm changes and people's attention of informal learning, all of which challenge the planning and designs of college learning spaces.

Colleges and universities expand the emergence of many new campuses with new teaching buildings and supporting facilities, but the campus is lack of vitality. But only spatial transference during change of classes, the necessary activities happens in campus. Nowadays, collegial learning patterns are no longer simplex, so informal learning environment is becoming the important tool to realize the mission of higher education. Therefore, the informal learning space is the place to make up for the lack of higher education in addition to the 
classroom. The study on the mechanism of the informal learning space and learning input in campus is of great significance. Creating a high quality informal learning space will greatly improve the quality of higher education.

In the research field of learning investment, the learning environment plays an important role in the learning environment as the interaction mechanism between the individual and the environment(Kuh, 2001)[1]. And Pascarella pointed out the organizational characteristics of universities and school environment's influence on students' development is just indirect effect, whereas the students' preschool experience, interact degree with teachers and students, individual effort are the direct effects and the first factors of students' cognitive development and the academic achievement(Pascarella, 2005)[2]. In the research field of learning place, Radcliffe puts forward PST learning places framework, which includes three core elements: teaching method, space and technology.

From the two areas of research, we can find the function route "learning space -- interactive activities -- learning inputs"(Figure 1).

In this pathway, the focuses of this study are: How the informal learning places in college campus? What is the relationship between the spatial configuration and informal learning places? How to promote it?

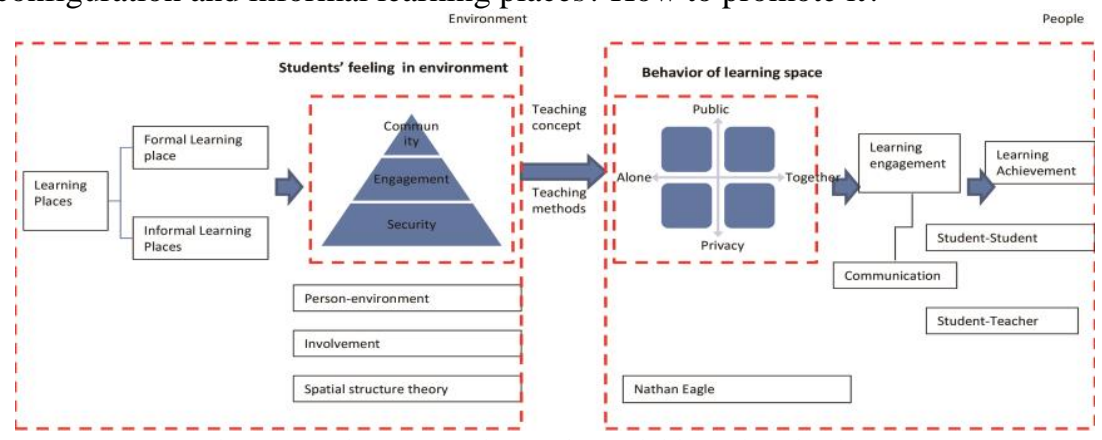

Fig.1. Learning space -- interactive activities -- learning inputs.

\subsection{Present research situation of home and abroad}

(1) College learning places

First of all, to create a high quality of informal learning places, it is necessary to carry out a correct description of it."Learning place" was studied since 1990s.We divide it into "formal learning place" and "informal learning place". The function of informal learning space includes material and spiritual. It can be divided into three categories: individual learning space, group learning space and collective discussion learning space(Tong Wu,2015)[3]. Lennie pointed that the formal learning place refers to the structured classroom experiences, or teacher-directed, where is the informal refers to more student- 
directed learning places. And she provided a theoretical concept called the "Rhythm of learning Framework"(Lennie, 2015)(Figure 2)[4].

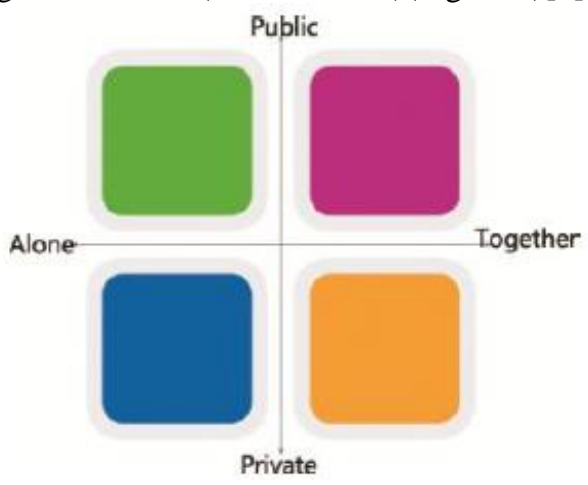

Fig.2. Rhythm of learning frame work.

James Allen pointed that knowledge innovation comes from people who have the "appropriate conceptual distance". Informal learning place provides the foundation that people who are in "appropriate conceptual distance" happening to meet and talk. It can promote the people to meet the "right one" to establish a new link. Greene pointed that the higher Integration, the more teachers and students know each other and the communication with other colleges(Greene,1997)[5].These studies had found that reasonable spatial layout would promote communication, promote cross disciplinary communication, stimulate the vitality of the campus, and promote sustainable development.

(2) Property of campus' spatial configuration

The campus informal learning place is related to the external spatial configuration. Hillier pointed out that in the urban people would choose the shortest angular path to get a destination. Although there are many paths that metric is much shorter, these paths exist a large number of turns. But in the university campus, everyone is familiar with the road. So whether the angular model proposed by Hillier is still applicable to the college campus is worth further verification. Therefore, it is important to establish the correct model of the university campus[6,7].

\section{Research Method}

\subsection{Informal learning space current situation investigation method}

The weekday (Thursday) and the weekend (Sunday) were selected to carry out activity annotation and flow data of counting method.

(1) Activity annotation method 
According to the college schedule, a day is divided into nine time periods, getting the statistics of the social property of the user's social attributes, spatial location, and interaction behavior of a certain moment in the science and engineering building area.

(2) Counting method

According to the college schedule, a day is divided into nine time periods, getting the statistics of the flow of people and social property from the 22 main sections of the science and engineering building within 10 minutes(Figure 3).

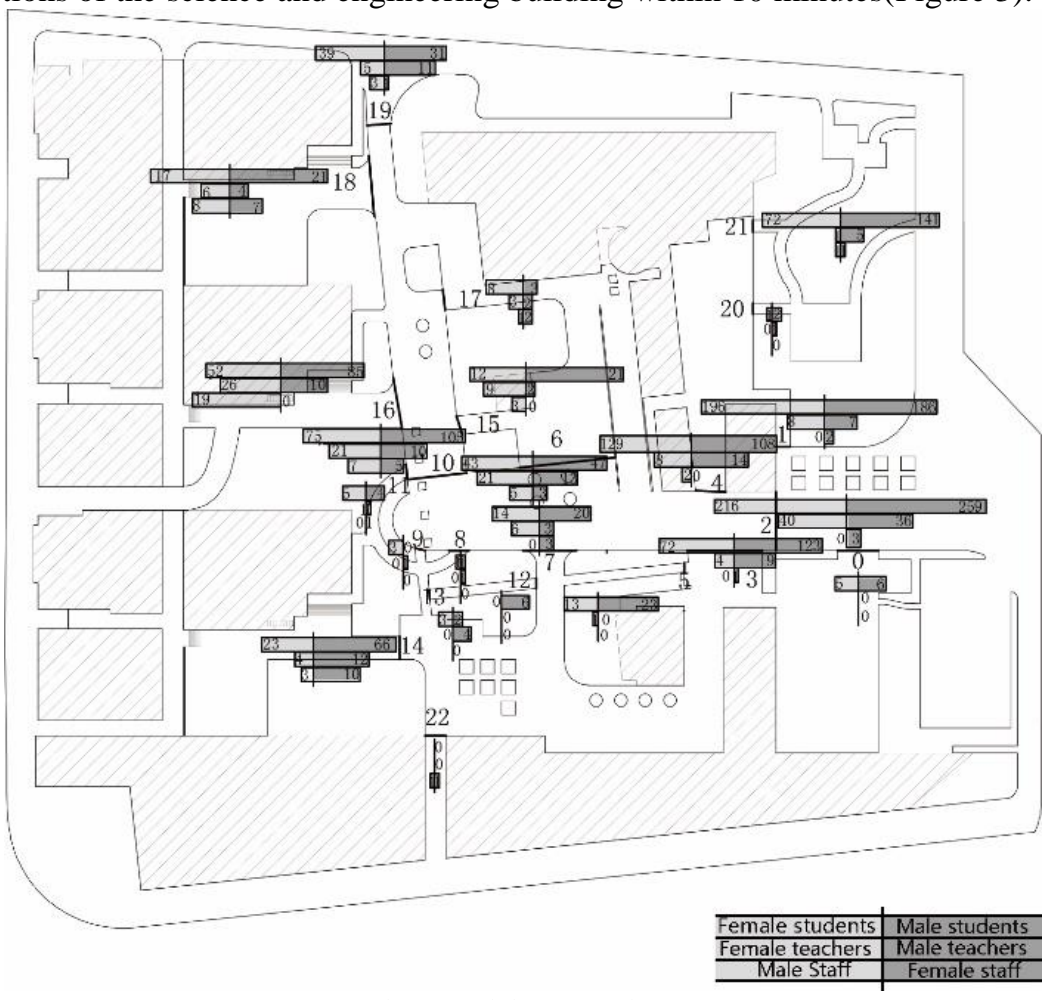

Fig. 3. Activity annotation.

\subsection{Correlation analysis method of interactive activities and spatial configuration}

The members analyze the is isovist, axial, segment of the science and engineering building area. Due to the situation that the north of it is the river, the west and south are walls on campus, and the main entrance connected to the campus is located in the northeast and the east directions. Therefore, the entrance is set as a selection set, and the different depth analysis of the area of it is carried out. At the same time, the information of the activity annotation on 
Thursday at 11:50 is taken as the representative, and the correlation is analyzed qualitatively.

First of all, analyzing the axial, the segment model of the whole campus and the science and engineering building area, obtains the spatial configuration of the quantitative data. Secondly, the traffic situation getting from counting method is divided into three kinds as follows: first, six social attribute classifications; second, two social attribute classifications (males and females); third, the number of all people as one group. Analyzing the two groups of spatial configuration data and three kinds of interactive network data, from which chooses typical data shows in the Table 1 and 2.

Table 1. Data of correlation analysis(axial model)

\begin{tabular}{l|cccccc}
\hline Spatial parameter & $\begin{array}{c}\text { Average } \\
\text { Male } \\
\text { Student }\end{array}$ & $\begin{array}{c}\text { Average } \\
\text { Female } \\
\text { Student }\end{array}$ & $\begin{array}{c}\text { Average } \\
\text { Male } \\
\text { Teacher }\end{array}$ & $\begin{array}{c}\text { Average } \\
\text { Female } \\
\text { Teacher }\end{array}$ & $\begin{array}{c}\text { Average } \\
\text { Male } \\
\text { Staff }\end{array}$ & $\begin{array}{c}\text { Average } \\
\text { Female } \\
\text { Staff }\end{array}$ \\
\hline Choice & $.710^{* *}$ & $.684^{* *}$ & $.647^{* *}$ & $.483^{*}$ & -.172 & .033 \\
Connectivity & $.693^{* *}$ & $.669 * *$ & $.564^{*}$ & $.489 *$ & -.167 & .060 \\
Control & $.640^{* *}$ & $.620^{* *}$ & $.533^{*}$ & $.339^{*}$ & -.134 & .203 \\
Integration $[\mathrm{HH}]$ & $.544^{*}$ & $.516^{*}$ & $.555^{*}$ & $.483^{*}$ & -.118 & -.003 \\
\hline
\end{tabular}

Table 2. Data of correlation analysis(segment model)

\begin{tabular}{l|cccccc}
\hline Spatial parameter & $\begin{array}{c}\text { Male } \\
\text { Student }\end{array}$ & $\begin{array}{c}\text { Female } \\
\text { Student }\end{array}$ & $\begin{array}{c}\text { Male } \\
\text { Teacher }\end{array}$ & $\begin{array}{c}\text { Female } \\
\text { Teacher }\end{array}$ & $\begin{array}{c}\text { Male } \\
\text { Staff }\end{array}$ & $\begin{array}{c}\text { Female } \\
\text { Staff }\end{array}$ \\
\hline Connectivity & .165 & .093 & .066 & .063 & -.361 & 0.000 \\
T1024 Choice & $.705^{* *}$ & $.691^{* *}$ & $.610^{* *}$ & $.657^{* *}$ & -.211 & .042 \\
T2014 integration & $.439^{*}$ & .388 & $.503^{*}$ & .393 & -.191 & -.071 \\
\hline
\end{tabular}

**Strongly Correlated

* Correlated

\section{Research Result}

\subsection{The current situation of informal learning space and interactive activity}

After the inspection, in the science and engineering area, most of the informal places are public, communal and lacking spaces of private property (Figure 4). And the quantity and quality of it are unsatisfactory or even in deficiency. It is known that the campus is short of vitality, and all the activities are almost necessary, and few people are talking in these areas.

The number of flowing people counted on weekday (Thursday) is 239, and it is 42 on weekend (Sunday). The number of walking contains $93.3 \%$ and $88.1 \%$, which shows that there are seldom spontaneous and social activities. Among all activities happened in the space, there is even no "sitting". The number of people in "talking" contains $36.4 \%$ on weekday, and $35.7 \%$ on 
weekend. The number of people in "static state" contains only 5.4\% and 7.1\%. Such a small proportion shows that the layout of informal learning spaces is quite unreasonable.

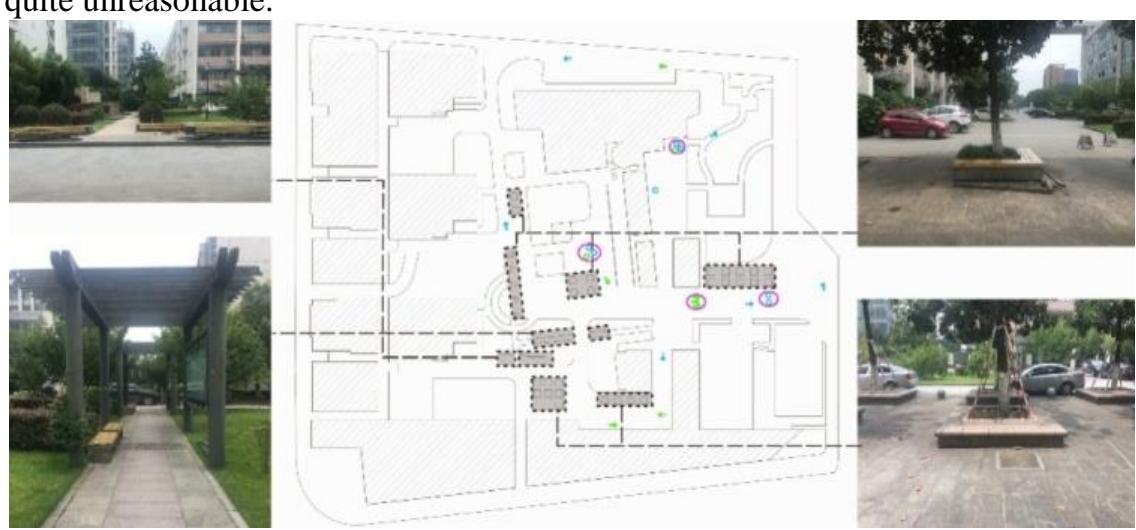

Fig.4. The statusmap of informal learning place.

\subsection{The influence of thespatial configuration and the interactive activity} on campus

(1) The relationship between interaction and spatial depth

People willing to stay in the region with shallower visibility step and angular step through the comparison with the activity annotation in different moment(Figure 5). They are willing to choose the path whit the shortest metric distance. At the same time, the static conversation occurs more in the overhead area of buildings and under the shade of the trees. There are some benches for students and teachers. But actually, there are almost no "sitting" behavior. What is the cause of the problem?

(2) The relationship between interaction and axial model

The correlation analysis for the quantitative and flow data of counting method about the spatial structure shows that the Choice has the highest correlation with the flow of people. In addition, Integration[HH],Total Depth and RA-R3 all have high correlation with the visitors flow rate.

(3) The relationship between Interaction and segment model

The analysis result of the segment diagram is approximately the same as the axial line. The establishment of the segment model is based on the change of the angle, and the axial model is based on the path. We ignore the social attributes of the active crowd and add all the interactive stream of people to get the total flow of people and do analysis. It can be found that the relationship between the visitors flow rate and the spatial structure characteristics of the axial line is higher. This confirms the above conjecture: people are more inclined to choose the shortest-path through the metric distance in campus. 


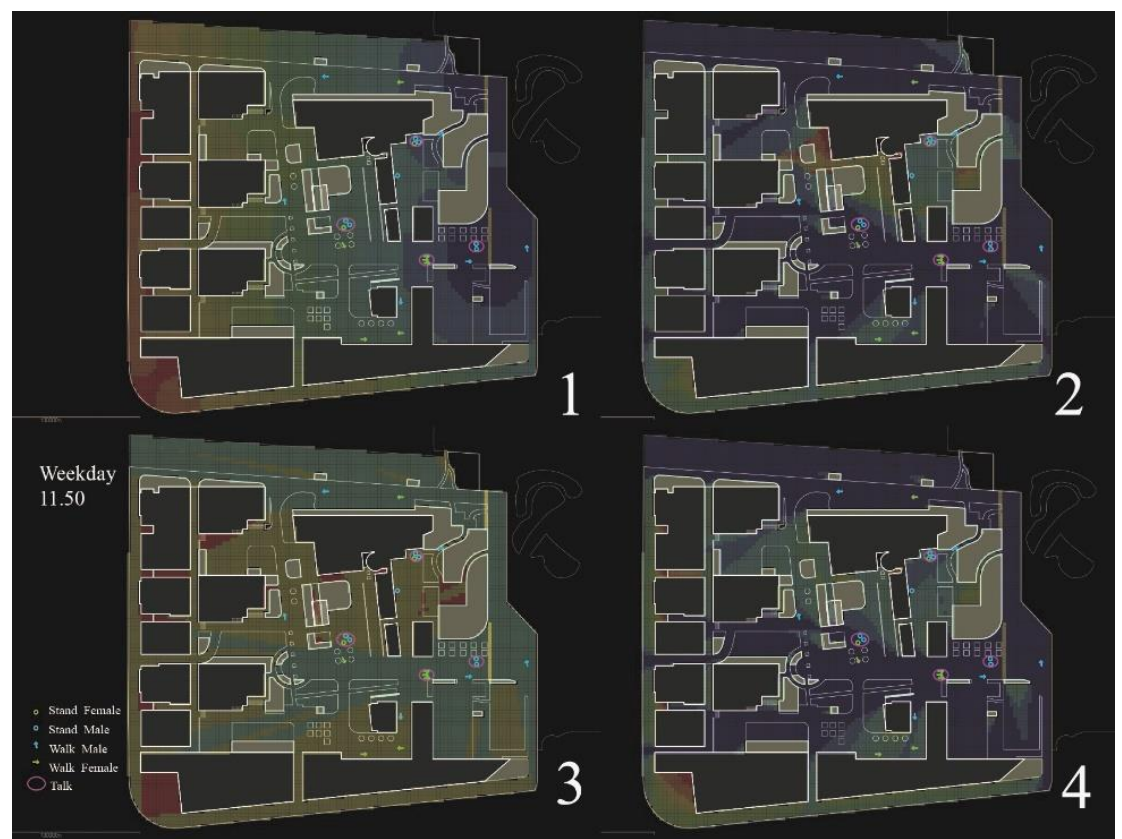

Fig.5. Activity annotation(1:Metric Step Shortest-Path Length 2:Metric Step Shortest-Path Angle 3:Visibility Step 4:Angular Step)

\subsection{The layout strategies of informal learning places}

Based on the spatial structure, to create excellent informal learning places and arouse campus vitality, the layout strategies of informal learning places for college campus should abide by the following strategies:

(1) You should plan the informal learning places in the area with more higher Choice, Integration, RA-R3 and Control;

(2) You should plan the informal learning places in the area with shallower Visibility Step and Angular Step;

(3) You should plan the informal learning places in the area with the shortest path through the distance metric;

\subsubsection{Application of layout strategies}

We analyze spatial structure about the area of the science and engineering building in this case. According to the layout strategies, informal learning places should be arranged in the area with higher Choice and Integration, and it also named Warm area; with selected entrance to gather sight and shallower Angular Step; with the shortest-path through the metric distance. From this, we would focus on the study of the area shown in figure $6 \& 7$. In this area, Choice, Integration, RA-R3 and Control are reflected in the warm. Meanwhile, the 
visibility step and the angular step are most shallow here. By the model of the axial of the group structure data shows, Integration is 1.81 (average Integration is 1.46) and Choice is 332 (average Choice for 140.13).
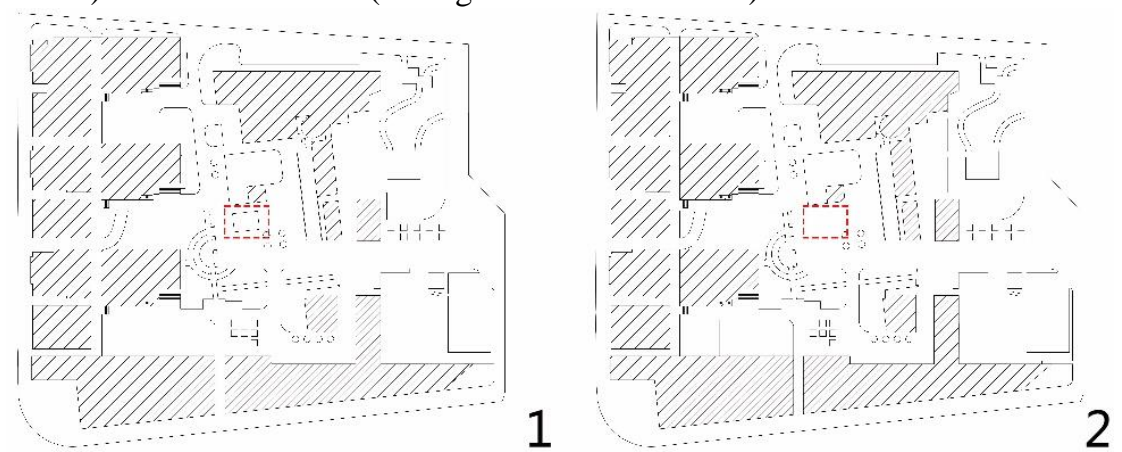

Fig.6. Survey Region left: before right: after.
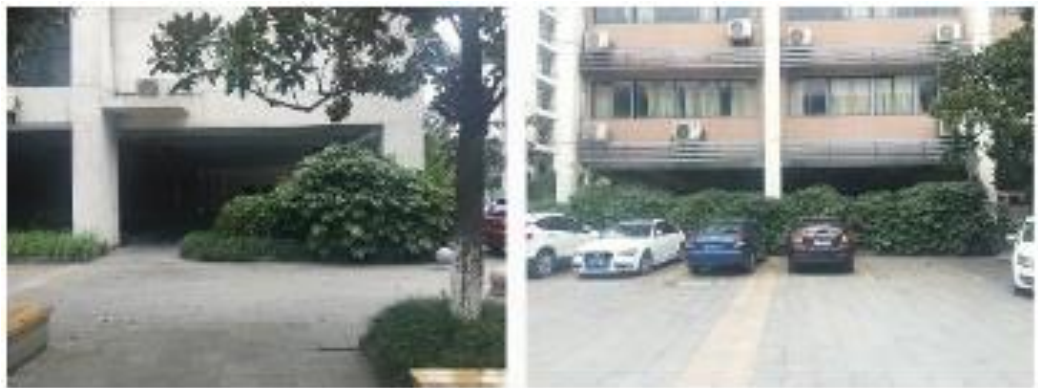

Fig.7. Current Situation.

If we plan informal learning places here, the spatial attribute would change. The space changes into the visual and accessible[8].

(1) Segment analysis

After an increased segment in this area. We calculate the Integration and Choice. The overall Integration of mean value increased by $0.28 \%$, and the Choice of the mean value increased by $3.42 \%$ (Table 3 ).

Table 3.Spatial structure analysis.

\begin{tabular}{l|lll}
\hline Spatial parameter & Before & After & Increase value \\
\hline T1024 Integration & 64.86 & 65.04 & $0.28 \%$ \\
T1024 Choice & 841.83 & 870.65 & $3.42 \%$ \\
\hline
\end{tabular}

(2) Isovist graphic analysis

As is shown(Figure 8), the modified regional tends to warm. After the transformation of the highest Integration of the area is significantly extended to the North road. The potential for reaching the stream of people has been 
improved. This means that the northwest corner of the space utilization rate is very low, it was "shielded" in the structure. While the small adjustment of spatial structure, the northwest corner of the teaching building has been significantly optimized. The area of the yellow green area with higher Choice is larger, and also extends to the northwest corner.
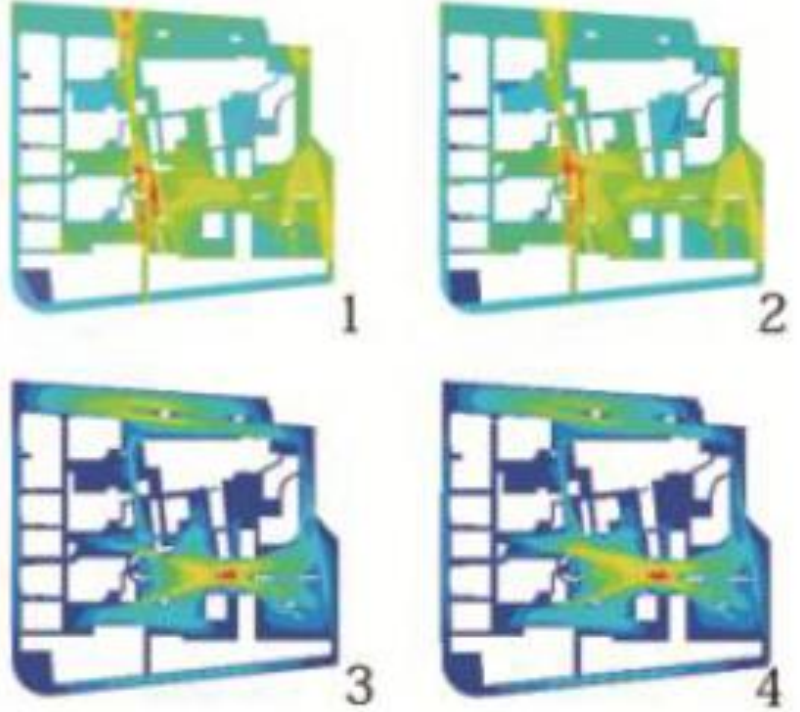

Fig.8. 1\&2:Integration, 3\&4:Choice.
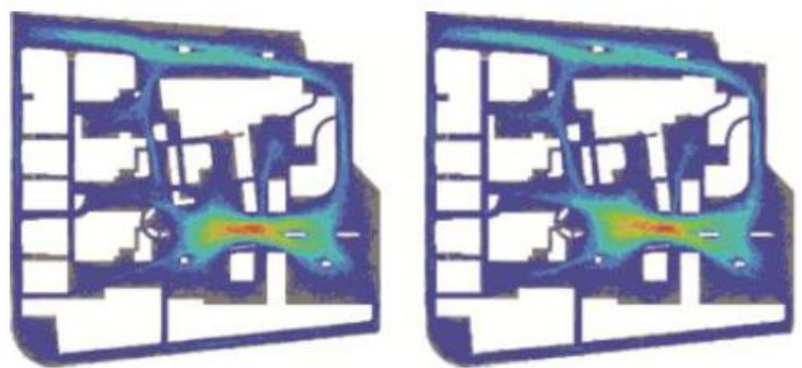

Fig.9. Agent analysis left: before right: after

(3) Agent analysis

Finally, the 5000 Agents are put into the area, so that they are repeated in which the random movement, so as to simulate the flow of people model (Figure9).After calculation we know that before the application of the layout strategies the average flow is 16.57 people, and after the application the average flow is 18.07 , which is increase $9.05 \%$. 


\subsubsection{Summary}

Therefore, we can draw a conclusion: it is suitable for the layout of the informal learning places and spatial structure has been greatly improved. According to space properties, Here could be the interactive space such as coffee or tea. Such spaces are mainly covered in the four quadrants include Public/Together and Public/Alone mode. In order to better meet the needs of users, in this space can use translucent partition, adding some speech privacy, visual privacy Private/Alone of space and Private/Together space.

\section{Discussion and Conclusion}

This paper expounds the importance of informal learning places in university education and puts forward the layout strategies. In order to achieve the final goal of improving the learning achievement. Criteria for the evaluation of learning performance is college students learning engagement. Therefore, in order to explain the accuracy of the informal learning space layout strategies, the next step of research should be taken to obtain the information of College Students' learning engagement by questionnaire survey. To reveal the mechanism of the function of informal learning space and learning engagement by "learning space -- interactive activities--learning inputs".

At the same time, in this example, haphazard is existed because of few data samples of the activity note and the section counting method. In some ways, there is almost no social and spontaneous activity in this case. It can only prove the lack of informal learning places in the universities. But it is unable to explore the users' feature of interactive activities in the high quality informal learning space. Therefore, it would be better to carry out some relevant analysis in other colleges to avoid the haphazard of a single case in the future. And we should have a further practice to test the strategies in the domestic and foreign universities, which are excellent in informal learning places.

\section{References}

1. Kuh.G.D. Assessing What Really Matters to student Learning Change: Inside the National Survey of Student Engagement [J].Change.2001,33(3): 10-17.

2. Pascarella, E.T., Terenzini, P.T. How College Affects Students, Volume 2: A Third Decade of Research[M].San Francisco: Jossey-Bass Publishers, 2005.

3. Tong Wu, Jian-Min Su, Jian-Xiong Yang, Wang-Da Zhu. Study on the informal learning space of college teaching building_-At Westminster 
College as an example [J]. Architecture and culture, 2015, (11):158-159. (In Chinese)

4. Lennie Scott-Webber. Informal Learning places_-Often forgotten but it is very important for students to learn;It is time to do a new design thinking![J], 2015, (2):28-43.

5. Greene M,Penn A, Socio-spatial Analysis of Four University Campuses: The Implications of Spatial Configuration on Creation and Transmission of Knowledge[C]. Seoul: Space Syntax Seoul Organising Committee. Space Syntax First International Symposium,1997:13.1-13.16.

6. Hillier B.,Penn A. Visible colleges : structure and randomness in the place of discovery [J].Science in Context,1991,4(1):23-50.

7. Hillier B. and Hanson J. The Social Logic of Space [M].Cambridge: Cambridge University Press, 1984:18-26.

8. Tao Yang, Qiang Sheng, Ning Liu, The Voids May Become Useful: An Application of Space Syntax in Commercial Building Design, DOI:10.1644/j.wa.2015.04.018.(In Chinese) 